\title{
A CRIAÇÃO DO CONHECIMENTO CORPORATIVO PROMOVIDO PELOS FLUXOS DE INFORMAÇÕES GERADOS NA IMPLANTAÇÃO DO PLANEJAMENTO ESTRATÉGICO
}

\author{
THE CREATION OF THE CORPORATIVE KNOWLEDGE \\ PROMOTED BY THE FLOWS OF INFORMATION GENERATED IN \\ THE IMPLANTATION OF THE STRATEGICAL PLANNING
}

\author{
Moacir José Michelon (UTFPR) \\ Mestrando em Engenharia da Produção \\ Universidade Tecnologica Federal do Paraná - Campus Ponta Grossa \\ Av. Monteiro Lobato Km 04 CEP 84016-210, Ponta Grossa, PR. \\ Telefone 4121178340 moacir_2005@pg.cefetpr.br \\ Luiz Alberto Pilatti \\ UTF/PR Campus Ponta Grossa - PR
}

Professor Doutor do Departamento de Pós Graduação do Curso de Engenharia de Produção

Av. Monteiro Lobato, s/n ${ }^{\circ}-$ Km 04. CEP: 84016-210 - Ponta Grossa - PR

Fone: (042)32204805 lapilatti@pg.cefetpr.br

Isaura Alberton de Lima (UTFPR)
UTF/PR Campus Ponta Grossa - PR

Professora Doutora do Departamento de Engenharia da Produção

Av Sete de Setembro 3165 . CEP 80230-901 Curitiba PR

Fone-(41) 33104427 alberton@cefetpr.br

Hélio Gomes de Carvalho (CEFET-PR) gomes@ppgte.cefetpr.br

Professor Doutor do Programa de Pós-Graduação em Engenharia de Produção

Universidade Tecnológica Federal do Paraná

Núcleo de Gestão de Tecnologia e Inovação - (41) 3310-4786

helio@cefetpr.br 


\title{
RESUMO
}

Esta pesquisa tem como objetivo analisar como os fluxos de informações gerados na concepção e realização do planejamento estratégico provocam a criação do conhecimento organizacional e, por conseqüência, a gestão dos 'diferentes conhecimentos' na organização, o que permite a formulação de um adequado planejamento estratégico. A metodologia utilizada foi de pesquisa documental e a observação participante na concepção e realização do planejamento estratégico em empresa do ramo de alimentos e bebidas. Constatou-se que a estruturação do planejamento estratégico proporciona fluxo de informações partindo de várias fontes, possibilitando a disseminação e criação de conhecimento em toda a empresa, ampliando o conhecimento organizacional. Com a estruturação do planejamento estratégico as ações de toda a empresa apresentaram-se alinhadas, proporcionando à empresa o melhor aproveitamento de oportunidades reduzindo os pontos fracos e ampliando os pontos fortes, oportunizando a participação de todos os colaboradores, contribuindo com a soma dos diferentes conhecimentos.

Palavras-chave: Planejamento estratégico, Criação de conhecimento, Gestão da inovação.

\begin{abstract}
The objective of this research was to analyze how the flood of information generated in the conception and accomplishment of the strategical planning incites the creation of the organizational knowledge, and for consequence, the management of the different knowledge ' in the organization what makes possible the formularization of one adequate strategical planning. The used methodology was of documentary research and the participant comment in the conception and accomplishment of the strategical planning in a company of foods and drinks. It was verified that the organization of the strategical planning provides a flood of information derived from several sources, and making possible the dissemination and creation of knowledge in all company, extending the organizational knowledge. With the organization of the strategical planning the actions of all the company had been presented lined up, providing to the company the best exploitation of chances reducing the weak points and extending the strong points, giving the opportunity of all collaborators contributing with the addition of the different knowledge.
\end{abstract}

Key words: Strategical planning, Creation of knowledge, Management of the innovation.

\section{INTRODUÇÃO}

A globalização dos mercados acirrou a competitividade entre as empresas. A facilidade de acesso dos investidores ao mercado de ações a praticamente todos, também aumentou a competitividade das empresas no mercado de ações. Cada vez mais a empresa precisa apresentar solidez e rentabilidade. Para conseguir melhorar sua rentabilidade de forma 
constante e reduzir seus riscos, as empresas necessitam de um sistema de gestão que proporcione o desenvolvimento de ações direcionadas a realizar da melhor forma as atividades que realmente geram valor para a empresa.

Para saber fazer as coisas certas, o sistema de gestão precisa usufruir do conhecimento de seus colaboradores e promover a criação do conhecimento corporativo, pois cada vez mais as empresas valem pela capacidade de agregar conhecimento aos seus produtos e serviços. Para promover a criação do conhecimento faz-se imprescindível identificar os conhecimentos que a empresa necessita para atender aos novos desafios e, após identificá-los é preciso buscar as fontes fornecedoras destes conhecimentos. Conhecendo a necessidade e as fontes de conhecimento, o passo mais complexo consiste em promover a disseminação e a incorporação desse conhecimento, promovendo um ambiente para sua criação.

Probst et al. (2002, p. 63) relatam que "os administradores freqüentemente suspeitam que o conhecimento que desejam existe em algum lugar. O que lhes falta é uma maneira de acessar o ambiente de conhecimento e de identificar tipos específicos de conhecimentos, tanto interno como externamente". Para promover um ciclo de aprendizagem organizacional foi necessário entender como os fluxos de informações são gerados na empresa de forma a promover a criação de conhecimento. O problema identificado é que os fluxos de informações não fluem de forma adequada nas organizações impedindo que as informações produzam conhecimento, não contribuindo com a melhoria do processo.

Considerando que a administração estratégica consiste na relação entre pensamento e ação, controle e aprendizado, estabilidade e mudança (MINTZBERG et al. 2000), estruturar um plano estratégico pode contribuir com a orientação e organização dos diferentes conhecimentos da organização.

O planejamento estratégico vem sendo amplamente utilizado como ferramenta para definir e atingir metas de resultados superiores nas grandes corporações. Esses resultados são atribuídos ao alinhamento das ações dos colaboradores para atender às expectativas de rentabilidade dos acionistas. Analisando o processo de concepção e execução do planejamento estratégico percebeu-se a existência de um intenso fluxo de informações.

Esses fluxos buscam, primeiramente, comunicar as estratégias e, posteriormente, identificar oportunidades e medidas para a obtenção destes resultados superiores. Quando um resultado é analisado, discutido e definida uma contra medida ou um novo conhecimento é identificado, transcrito, difundido e assimilado pela equipe, ocorre a multiplicação do conhecimento. Este processo de multiplicação do conhecimento ocorre em quatro tipos de 
conversão, sendo estes: socialização, externalização, combinação e internalização (NONAKA; TAKEUCHI, 1997).

Os fluxos de informações promovem a criação de conhecimento na organização. Uma análise sobre a criação do conhecimento através dos fluxos de informação possibilitou um melhor entendimento sobre a criação de conhecimento. O entendimento da criação do conhecimento pode auxiliar os gestores, proporcionando melhor utilização destes meios para que as metas sejam atingidas, suportada por um aporte de conhecimento criado na própria organização.

\section{A EMPRESA E SUA RELAÇÃO COM O MERCADO DE AÇÕES}

Para se apurar o valor de mercado de uma empresa, soma-se a quantidade de ações que compõem a divisão do capital e multiplica-se pelo valor que está sendo negociada a ação. Este valor de mercado, deduzido o capital nela investido pelos acionistas ou sócios, forma o Market Value Added - MVA - que é o valor de mercado adicionado (OLIVEIRA et al., 2002). O preço de mercado dos títulos é resultante do confronto das forças de oferta e demanda de título entre os negociantes, o que para o investidor a existência de uma relação positiva entre risco e retorno esperado deve ser evidente (GITMAN, 2002). Para tanto, Iudícibus et al. (2001, p. 180) definem que "risco significa a possibilidade de perda financeira (...) medido pelo desvio-padrão em torno da esperança matemática do retorno", e ainda Iudícibus et al. (2001, p. 179) definem que "retorno do capital refere-se ao lucro obtido em relação ao capital investido".

A preocupação da empresa em obter um retorno financeiro adequado é evidente, pois assim como outros recursos, o capital é limitado e há um custo envolvido no projeto em que será feito o investimento, não bastando que o investimento apresente como resultado apenas a expansão das atividades da empresa, é preciso que gere lucro maior que o custo do capital nela investido.

Custo do capital é a taxa de retorno que a empresa precisa obter sobre seus investimentos para manter o valor de mercado de suas ações, é o retorno exigido pelos fornecedores de capital para manter o investimento na empresa (GITMAN, 2002). Segundo Oliveira et al. (2002, p.184), "o objetivo principal de todas as empresas deve ser a maximização dos lucros dos detentores de capital, isto é, remunerar os donos do dinheiro". Diante dos cenários apresentados pelo mercado e pelos resultados e perspectivas das 
empresas, analistas de mercado emitem pareceres. Estes pareceres têm por objetivo orientar o investidor a comprar, vender ou manter as ações de determinadas empresas. A Corretora de Valores Sólidus S/A utiliza a seguinte classificação para as ações (Quadro 1).

Quadro 1 - Classificação de ações.

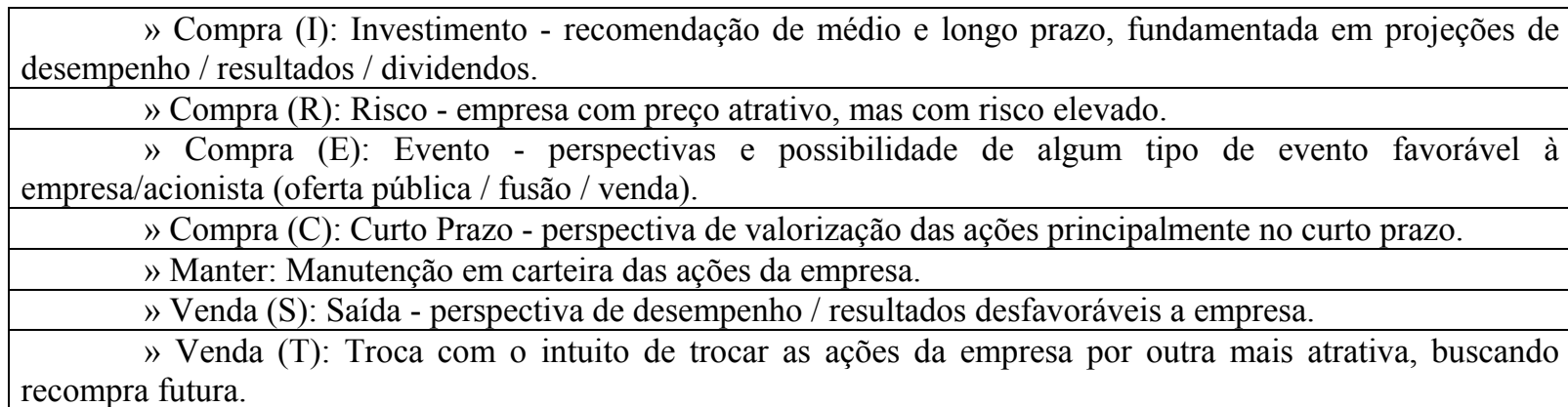

Fonte: Site da Corretora de valores Sólidus.

Como apresentado no quadro 1 , manter a perspectiva de desempenho lucrativo e assegurar a perpetuidade da empresa ao acionista é de extrema importância, pois influencia de forma positiva a classificação feita pelas corretoras. É baseado nestas orientações que grande parte dos investidores efetua suas operações de compra ou venda das ações da empresa.

\section{CADEIA DE AGREGAÇÃO DE VALOR}

Tradicionalmente, a atuação dos executivos é voltada para o desenvolvimento de estratégias competitivas, com produtos e serviços com qualidade e inovação superiores, que ofereçam melhor lucratividade e redução de capital empregado (WAHBA, 2002). Ocorre que, após determinado período, mesmo com a implementação de sistemas complexos de gestão e controle, algumas empresas passam a gerar prejuízo econômico, desvalorizando a empresa.

Para essas empresas, falta uma visão clara da geração da riqueza proporcionada pelos seus processos. É preciso perseguir a excelência operacional em busca da criação da riqueza (WAHBA, 2002). A perseguição da riqueza direciona os gestores a assumirem uma postura totalmente voltada para a obtenção de lucro econômico, conduzindo a empresa a melhor explorar seu potencial de geração de valor (WAHBA, 2002). O valor agregado está diretamente ligado à percepção do consumidor, este valor é percebido pelo grau de satisfação 
gerado pelos atributos ou benefícios que o produto oferece. A percepção do cliente ocorre em três passos da qualidade, sendo: a qualidade obrigatória, a qualidade competitiva e a qualidade atrativa (WAHBA, 2002), conforme figura 1.

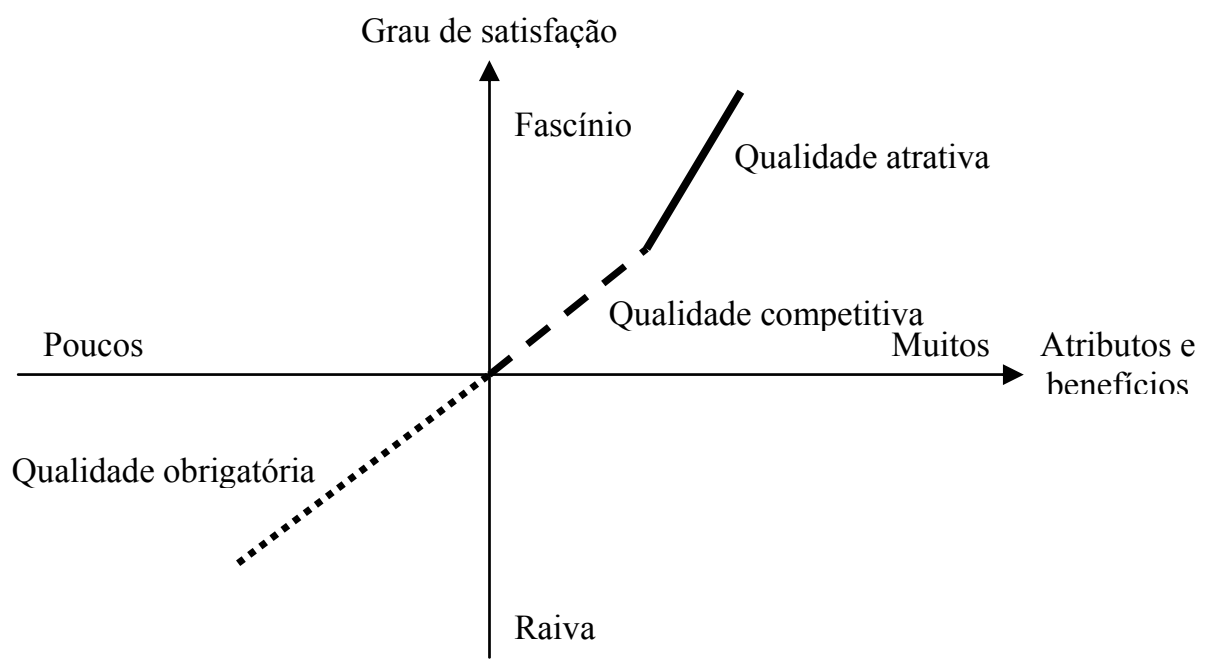

Figura 1 - Criação da qualidade inteligente.

Fonte: Wahba (2002, p. 122).

Qualidade obrigatória é a qualidade que existindo não é percebida e sua falta gera a insatisfação do cliente. Referem-se a primeira dimensão da qualidade, sendo requisitos básicos de adequação e confiabilidade exigidos do produto (WAHBA, 2002). Qualidade competitiva é a atribuição de elementos intangíveis aos elementos tangíveis do produto, como informação, conhecimento ou serviços, com o fim de criar uma satisfação maior que a oferecida pela concorrência (WAHBA, 2002).

Qualidade atrativa é a qualidade desconhecida pelo cliente e que quando proporcionada, cria o encantamento ou fascínio do cliente pelo produto ou serviço (WAHBA, 2002). Na visão de lucro econômico, a qualidade inteligente resume-se em realização de lucro operacional, maior que o custo do capital empregado (WAHBA, 2002). Porter (1990, p. 2) afirma que" a vantagem competitiva surge fundamentalmente do valor que uma empresa consegue criar para seus compradores e que ultrapassa o custo de fabricação pela empresa". Para Kaplan, Norton (1997), a cadeia de agregação de valor para o cliente compreende os processos entre a identificação das suas necessidades até o atendimento das necessidades do cliente, garantindo sua satisfação, conforme figura 2.

\begin{tabular}{|c|c|c|c|c|}
\hline \multirow[b]{2}{*}{$\begin{array}{l}\text { Identificação } \\
\text { das } \\
\text { necessidades } \\
\text { dos clientes }\end{array}$} & Processo de inovação & Processo de operação & $\begin{array}{l}\text { Processo de } \\
\text { serviço pós- } \\
\text { venda }\end{array}$ & \multirow[b]{2}{*}{$\begin{array}{l}\text { Satisfação da } \\
\text { necessidades } \\
\text { dos clientes }\end{array}$} \\
\hline & $\left.\begin{array}{l}\text { Identificar } \\
\text { o mercado }\end{array}\right\}$ pr & \begin{tabular}{l|l} 
Gerar & Entre \\
produtos $/$ & produ \\
Serviços & Servi
\end{tabular} & $\begin{array}{l}\text { Serviços } \\
\text { ao clien }\end{array}$ & \\
\hline
\end{tabular}


Figura 2 - Cadeia de agregação de valor.

Fonte: adaptado de Kaplan, Norton (1997, p. 102).

No processo de inovação são identificadas novas necessidades e são pesquisados: a capacidade do mercado e os pontos de preço das linhas de produtos. São desenvolvidos produtos para atender estas necessidades e o produto é idealizado (KAPLAN; NORTON, 1997). O processo de operação baseado no pedido do cliente se constitui na produção e no fornecimento de forma pontual, regular e eficiente dos produtos aos clientes (KAPLAN; NORTON, 1997). No serviço pós-venda são oferecidos serviços de garantia e suporte técnico aos produtos vendidos ou serviços prestados (KAPLAN; NORTON, 1997).

Este fluxo evidencia que as empresas precisam oferecer mais do que os produtos que fabrica, é preciso identificar e satisfazer as necessidades dos seus clientes com produtos e serviços. O trabalho inicia antes da produção e se encerra após a venda, garantindo a satisfação e o atendimento das necessidades dos clientes.

\section{PLANEJAMENTO ESTRATÉGICO}

Manter a competitividade da empresa em alta em meio às necessidades de mudanças muitas vezes radicais é um desafio permanente para todo administrador. Para obter melhor resultado é preciso definir a estratégia gerencial da empresa. A estratégia possibilita estruturar um plano em forma de perspectiva, tendo como base as intenções coletivas, verbalizadas e explicadas ou não, que refletem os recursos ou capacidades da organização (MINTZBERG, et al., 2000).

Oliveira (2001, p. 293) define estratégia como:

Ação relacionada com objetivos e desafios, e com modos de persegui-los, que afetam a empresa como um todo. É um conjunto de linhas administrativas básicas que especificam a posição da empresa diante dos seus produtos e mercados, as direções em que ela procura desenvolver-se ou 
transformar-se, os instrumentos competitivos que ela utilizará, os meios através dos quais entrará em novos mercados, a maneira pela qual configurará seus recursos, as potencialidades que procurará explorar e, inversamente, as fraquezas que procurará evitar. Representa a definição do caminho mais adequado a ser seguido pela empresa para alcançar uma situação desejada (OLIVEIRA, 2001, p. 293).

A estratégia é composta pela ordenação de conhecimentos e expectativas dos componentes da organização. A estruturação da estratégia deve compreender a síntese de uma quantidade muito grande de informações intangíveis direcionadas às novas perspectivas da organização (MINTZBERG, et al., 2000). A alta administração precisa organizar e alinhar estes conhecimentos de forma a direcionar as ações da empresa na realização das expectativas.

Para estruturar a estratégia da empresa é preciso construir um plano, no plano estratégico são relatadas e debatidas as estratégias propostas. Drucker (1998, p. 27) define este plano como o planejamento estratégico da organização, sendo este:

(...) o processo contínuo de, sistematicamente e com o maior conhecimento possível do futuro contido, tomar decisões atuais que envolvam riscos; organizar sistematicamente as atividades necessárias a execução dessas decisões e através de uma retroalimentação organizada e sistemática, medir o resultado dessas decisões em confronto com as expectativas alimentadas (DRUCKER, 1998, p. 27).

Toda empresa possui algum tipo de plano e ações estratégicas que de alguma forma são implementadas (OLIVEIRA, 2001). Estruturar esses planos e ações é objetivo da metodologia dos diferentes planos estratégicos. Com o planejamento estratégico a empresa espera conhecer e melhor utilizar os pontos fortes, identificar e minimizar seus pontos fracos, levantar e aproveitar as oportunidades e evitar as ameaças.

Definir metas, traçando objetivos de longo prazo e traçar maneiras e ações para alcançá-los, transformando aspirações em realidade é a base de um planejamento estratégico. Segundo Oliveira (2001, p. 43), “(...) o planejamento pode se distinguir em três tipos: o planejamento estratégico - desenvolvido pela alta administração; o planejamento tático desenvolvido pela média administração; o planejamento operacional a ser desempenhado pela equipe de chão de fábrica", conforme figura 3. 


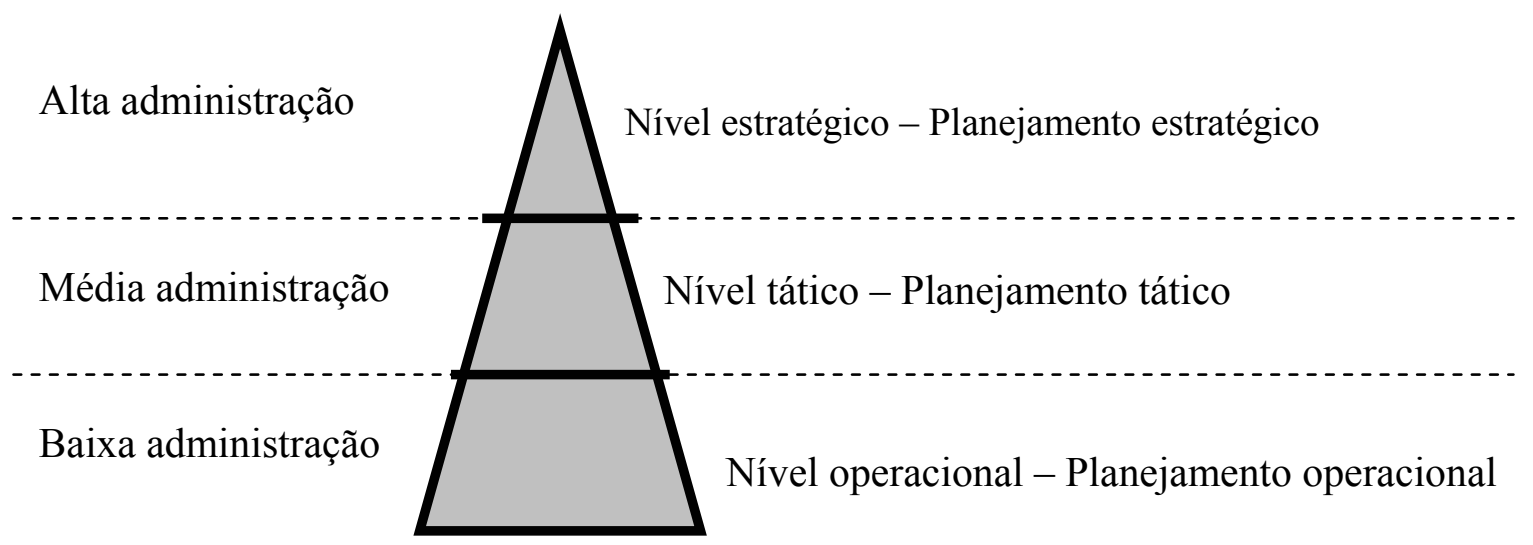

Figura 3 - Níveis de decisão e tipos de planejamento.

Fonte: Oliveira (2001, p. 43).

Oliveira (2001, p. 62) nos relata que “(...) o Planejamento estratégico possui três dimensões operacionais: delineamento, elaboração e implementação”. O delineamento é a definição da estrutura do processo onde é definida a metodologia a ser usada, a equipe que será envolvida no planejamento estratégico e os profissionais responsáveis.

$\mathrm{Na}$ elaboração são identificadas as ameaças e oportunidades apresentadas pelo cenário externo, também é avaliada a estrutura interna da empresa, levantando-se competências e fraquezas da organização e a busca de alternativas para a obtenção de vantagens e conhecimento de prováveis riscos. São identificados os objetivos a serem atingidos com o gerenciamento estratégico. Estes objetivos devem atender as expectativas dos acionistas.

Para implementação são realizados treinamentos, divulgação das ações e são oferecidos benefícios aos colaboradores, nesta etapa são implementadas ações identificadas como necessárias para se atingir os objetivos do plano estratégico. Conforme modelo proposto por Oliveira (2001, p. 64), as fases básicas para a elaboração e implementação do planejamento estratégico podem ser as seguintes: diagnóstico estratégico, missão da empresa, instrumento prescritivo e quantitativo, controle e avaliação", conforme figura 4.

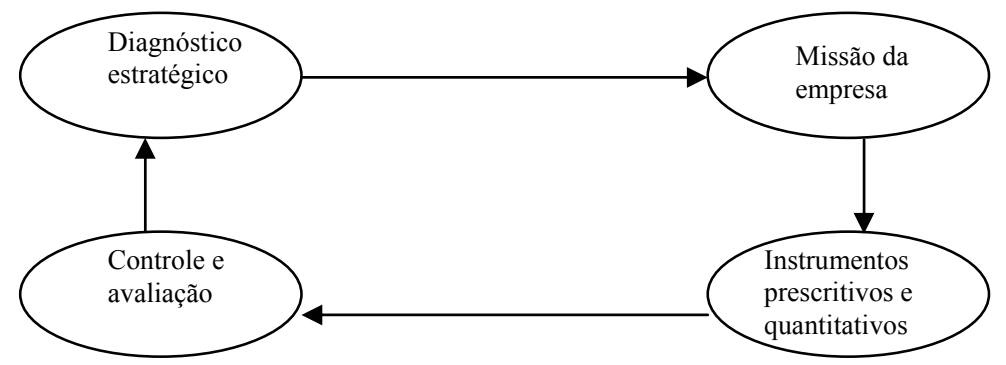


Figura 4 - Fases do planejamento estratégico.

Fonte: Oliveira (2001, p. 64).

Conforme nos relata Oliveira, no diagnóstico estratégico os colaboradores das diferentes áreas da empresa buscam avaliar como a empresa está tratando os aspectos internos e reagindo aos aspectos externos da empresa. Esta fase é dividida em quatro etapas, sendo a identificação da visão, a análise externa, a análise interna e a análise dos concorrentes (OLIVEIRA, 2001). A identificação da visão consiste em identificar a expectativa dos acionistas e da alta administração da empresa, nesta etapa busca-se vislumbrar o futuro às vezes ainda distante.

A capacidade de atingir esta visão é testada e avaliada com a análise das ameaças e oportunidades apresentadas pelo cenário externo. Na análise externa a empresa deve olhar para fora de si, buscando identificar as oportunidades e as ameaças expostas à empresa. Nesta etapa são visualizadas as maneiras de usufruir das oportunidades e evitar as ameaças. O cenário externo pode ser representado pelo mercado, pela evolução tecnológica, por aspectos econômicos, sociais e políticos, legislação e concorrência.

A competitividade de uma empresa depende de sua capacidade de aproveitar as oportunidades que o ambiente oferece melhor que seus concorrentes (KOTLER, 1980). As condições competitivas internas da empresa são avaliadas pela análise das forças, das fraquezas e dos pontos neutros, considerando o cenário externo como base para a avaliação. Nesta etapa são analisados a capacidade produtiva, a estrutura organizacional, a linha de produtos, seus sistemas de informações, o emprego de tecnologia, os recursos humanos e financeiros e a imagem da marca.

O ideal é que a empresa passe a usufruir de oportunidades oferecidas de forma a melhor aproveitar suas capacidades internas. A análise dos concorrentes é complementar a análise externa. Consiste em identificar as vantagens e desvantagens da empresa comparadas à de seus concorrentes, avaliando se a empresa está em melhores ou piores condições de aproveitar as oportunidades oferecidas pelo cenário externo em comparação a seus concorrentes.

\section{ANÁLISE SWOT}


Para se estabelecer uma estratégia adequada, primeiramente é preciso promover uma adequação da empresa entre os fatores externos e os fatores internos (MINTZBERG et al., 2000). Esta análise pode ser materializada através do uso da matriz SWOT, possibilitando o alinhamento da missão e visão da empresa às oportunidades oferecidas pelo ambiente externo.

A palavra SWOT é formada pelas iniciais das quatro palavras da língua inglesa envolvidas na análise: strengths - forças, weaknesses - fraquezas, opportunities oportunidades e threats - ameaças (HINDLE; LAWRENCE, 1994). Esta ferramenta possibilita fazer uma análise da situação em que a empresa se encontra, identificando suas forças e fraquezas e as oportunidades e ameaças do meio em que a empresa está envolvida (HINDLE; LAWRENCE, 1994). Após conhecer a situação da empresa, é possível definir o grau de adequação entre elas.

A empresa que apresenta pontos fortes alinhados aos fatores críticos de sucesso para satisfazer as oportunidades de mercado será certamente competitiva no longo prazo (HINDLE; LAWRENCE, 1994). Para dirimir as ameaças e reduzir os pontos fracos são estabelecidos objetivos estratégicos, estes objetivos visam a aumentar a competitividade da empresa. O uso da análise de SWOT possibilita maior eficiência no estabelecimento destes objetivos, pois são estabelecidos a partir da análise da empresa e do ambiente em que está atuando. Considerando a predominância de pontos fortes ou fracos e de oportunidades e ameaças, a postura estratégia adotada terá como objetivo buscar: o desenvolvimento, o crescimento, a manutenção, ou a sobrevivência da organização, conforme figura 5.

\begin{tabular}{|l|l|l|}
\cline { 2 - 3 } \multicolumn{1}{c|}{} & Pontos fortes & Pontos fracos \\
\hline Oportunidades & Desenvolvimento & Crescimento \\
\hline Ameacas & Manutenção & Sobrevivência \\
\hline
\end{tabular}

Figura 5 - Postura estratégica.

Fonte: adaptado de Oliveira (2001, p. 130).

O desenvolvimento ocorre com a predominância de pontos fortes e oportunidades, demonstrando que a empresa está preparada para assumir novos desafios, podendo a administração conduzir suas ações para o desenvolvimento da organização. $\mathrm{O}$ crescimento ocorre com a identificação de fraquezas da organização confrontando-se com oportunidades oferecidas pelo ambiente externo. A manutenção ocorre com a predominância de pontos 
fortes da empresa num cenário externo de ameaças, é comum nos mercados saturados. A sobrevivência ocorre quando as estratégias de sobrevivência são resultantes da análise das fraquezas da organização frente às ameaças do ambiente externo.

\title{
6 BALANCED SCORECARD
}

Saber descrever onde a organização quer chegar no futuro constitui os objetivos estratégicos da empresa, assim, Kaplan, Norton (1997, pp. 153 e 155) orientam que:

\begin{abstract}
As empresas que conseguem traduzir a estratégia em sistema de mensuração têm muito mais probabilidade de executar sua estratégia porque conseguem transmitir objetivos e metas (...) o sistema de mensuração deve explicitar as relações - hipótese - entre os objetivos - e as medidas - nas diversas perspectivas de modo que possam ser gerenciadas e validadas (KAPLAN, NORTON, 1997, pp. 153 e 155).
\end{abstract}

O sistema de gestão estratégica deve, conforme os mesmos autores (1997, p. 155) "identificar e tornar explícita a seqüência de hipóteses sobre as relações de causa e efeito entre as medidas de resultado e os vetores de desempenho destes resultados", possibilitando aos gestores conhecerem e acompanhar os resultados obtidos na realização dos objetivos estratégicos. O sucesso da organização passa a depender da assertividade na identificação dos objetivos estratégicos, pois conforme os mesmos autores (1997, p. 154) "se os objetivos e medidas certos forem identificados, a implementação provavelmente será bem sucedida".

Buscar o alinhamento das ações dos funcionários à estratégia da empresa, em busca da geração de valor é desafio constante de toda a organização. Para Kaplan, Norton (1997, p. 208) "para obter o máximo de beneficio, a equipe executiva deve compartilhar sua visão e estratégia com toda a empresa (...) cada indivíduo entende como sua atuação específica contribui com os objetivos da unidade de negócio". Com a abertura dos objetivos da empresa, segundo os mesmos autores (1997, pp. 207 e 208) nos relatam que "as organizações incentivarão ativamente seus funcionários a sugerir formas pelas quais a visão e a estratégia podem ser alcançadas".

Para possibilitar a comunicação e o envolvimento dos diferentes níveis de colaboradores e das diferentes áreas de conhecimento no longo prazo, os autores sugerem o ciclo do sistema de gestão estratégica composto por quatro passos: esclarecimento e tradução 
da visão e da estratégia, comunicação e estabelecimento de vínculos, planejamento e estabelecimento de metas e feedback e o aprendizado estratégico, conforme figura 6.

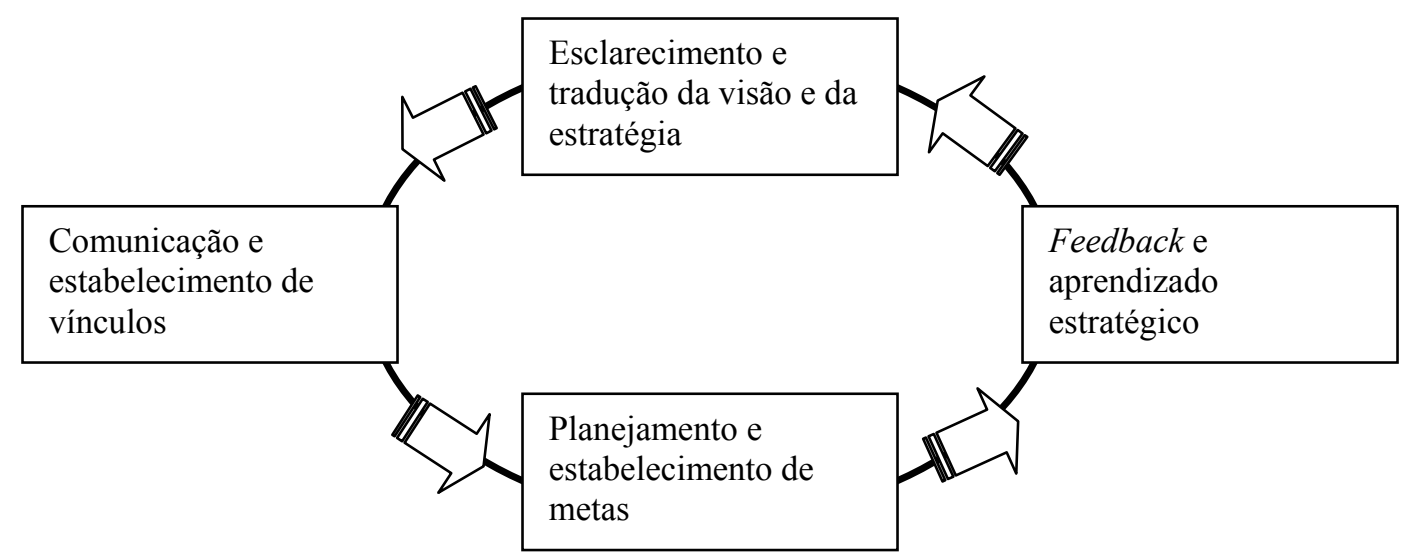

Figura 6 - Ciclo do sistema de gestão estratégica.

Fonte: adaptado de Kaplan e Norton (1997, p. 12).

Esclarecer e traduzir a visão e a estratégia - uma equipe alta administração representando as diferentes áreas de conhecimento, reúnem-se para esclarecer a estratégia e a partir dela, estabelecem objetivos estratégicos específicos para cada área. Na seqüência, os objetivos estratégicos específicos são traduzidos sendo identificados os vetores críticos para a realização dos objetivos estratégicos, para estes vetores críticos são estabelecidos metas (KAPLAN; NORTON, 1997).

Comunicação e estabelecimento de vínculos - o objetivo é levar ao conhecimento dos colaboradores, por meio de medidas operacionais específicas, os objetivos críticos e sua parcela de contribuição para que a estratégia da empresa seja bem sucedida. Com isso, as iniciativas locais de melhoria ficam alinhadas com as diretrizes estratégicas de longo prazo da empresa (KAPLAN; NORTON, 1997).

Planejamento e estabelecimento de metas - os altos executivos estabelecem metas de superação para os objetivos estratégicos específicos, estas metas devem ser atingidas num período de três a cinco anos (KAPLAN; NORTON, 1997).

Feedback e aprendizado estratégico - a construção do sistema de gestão, com sua ênfase na correlação causa e efeito, conduz ao raciocínio sistêmico dinâmico. Profissionais das diferentes áreas da empresa passam a entender como a empresa funciona, compreendendo a melhor forma de oferecer sua colaboração, contribuindo para a melhoria de toda a empresa. 
A análise dos indicadores e do ambiente possibilita aos gestores avaliar se as diretrizes estão adequadas (KAPLAN; NORTON, 1997).

A construção de um sistema de gestão possibilita a evolução uniforme no conhecimento. Para Kaplan, Norton (1997, p. 208) "Esse sistema de feedback e orientação engaja os funcionários no futuro da empresa e os encoraja a participar da formulação e da implementação da estratégia”. Para os mesmos autores (1997, p. 154) estas empresas "transmitem a estratégia por meio de um conjunto integrado de medidas financeiras e não financeiras".

Como proposta de uma ferramenta para estruturar informações de todo o complexo da empresa, surgiu a partir de uma pesquisa realizada no ano de 1990 o balanced scorecard, ferramenta que sugere a divisão da empresa em quatro perspectivas equilibradas, sendo: a perspectiva financeira, a perspectiva de processos, a perspectiva dos clientes e a perspectiva de inovação e aprendizado (KAPLAN; NORTON, 1997), conforme figura 7. 


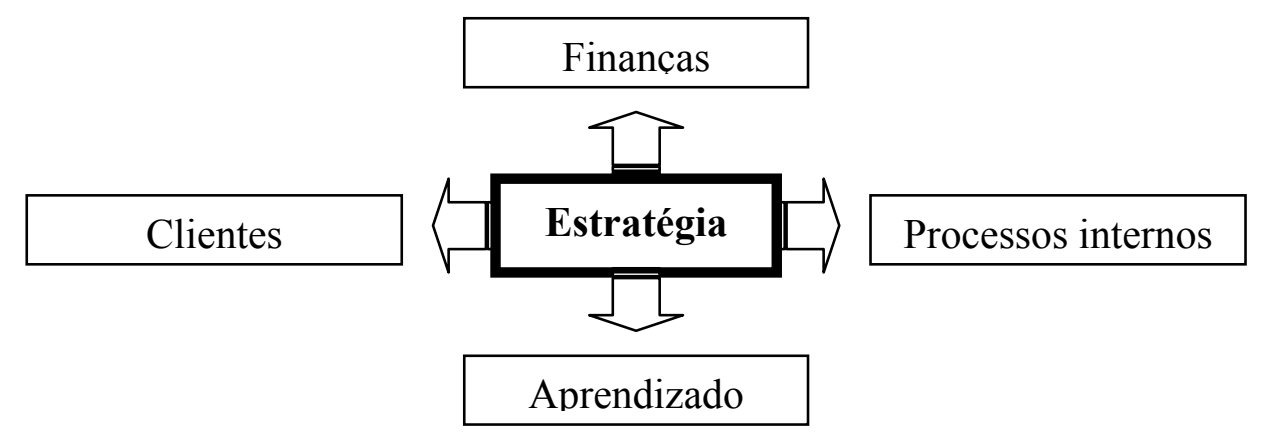

Figura 7 - Estruturação do balanced scorecard.

Fonte: Adaptado de Kaplan; Norton (1997).

$\mathrm{Na}$ perspectiva financeira são relacionados os indicadores de natureza econômica, financeira como lucratividade, liquidez, redução de custos, retorno sobre capital e redução dos riscos. As metas financeiras são estabelecidas com base na expectativa dos acionistas e serve de foco para os objetivos e medidas das outras perspectivas (KAPLAN; NORTON, 1997).

A perspectiva de clientes identifica os segmentos de clientes e mercados nos quais se deseja competir, considerando a lucratividade e a participação de mercado. Esta perspectiva compõe as fontes das receitas para atender os objetivos financeiros. A principal base de informação parte dos setores de marketing e vendas da empresa (KAPLAN; NORTON, 1997).

$\mathrm{Na}$ perspectiva dos processos internos são identificados os processos críticos de operação de cada área da empresa para a realização dos objetivos dos clientes alvos e acionistas. O objetivo é melhorar o desempenho financeiro com melhorias nos processos internos (KAPLAN; NORTON, 1997).

A perspectiva de aprendizado relaciona a situação do aprendizado e do crescimento organizacional. Visa a desenvolver a empresa para obtenção de resultados excepcionais na realização dos objetivos ambiciosos propostos nas perspectivas financeiras, de mercado e de processo internos (KAPLAN; NORTON, 1997).

O balanced Scorecard auxilia na implementação e esclarecimento dos objetivos estratégicos a toda a empresa. Esses objetivos estratégicos mobilizam os diferentes setores da empresa, atribuindo metas e desencadeando iniciativas estratégicas que visam a melhorar o desempenho (KAPLAN; NORTON, 1997). A utilização do balanced scorecard possibilita articular as estratégias de forma a garantir a sustentação do crescimento de indicadores financeiros e não financeiro, proporcionando maior consistência ao plano estratégico da empresa. 


\section{DA META AO PLANO de AÇÃo}

Uma meta é um objetivo a ser alcançado pela empresa, para Campos (1996, p. 45) "Uma meta é um gol. Um ponto a ser atingido no futuro. (...) Uma meta é constituída de três partes: um objetivo gerencial, um valor e um prazo". Para atingir as metas da alta administração são estabelecidas metas de melhoria aos processos. Campos (1998, pp. 164, 165) contribui: “Cada meta de melhoria gera um 'problema' (...). Para se atingir as metas de melhoria, utilizamos o método PDCA, que é (...) um 'método de se atingir metas', ou ainda, um "método de análise e solução de problemas". Método criado na década de 1920 por Shewhart, a sigla PDCA tem origem na língua inglesa e são as iniciais das palavras da língua inglesa plan (planejar), do (executar), check (verificar) e action (agir) (CAMPOS, 1996). As quatro etapas do PDCA são realizadas em oito passos, conforme figura 8.

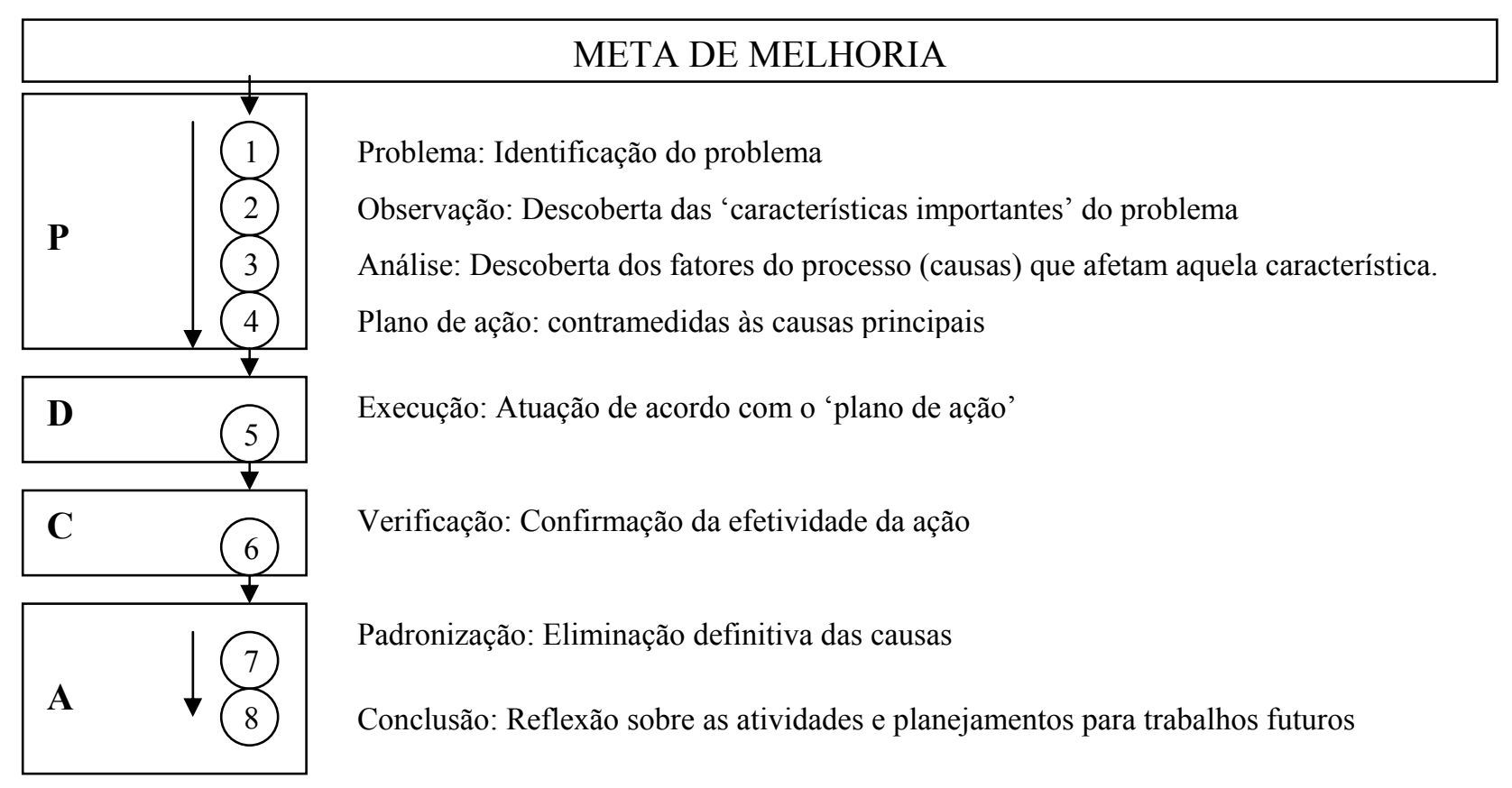

Figura 8 - Detalhamento do PDCA.

Fonte: Adaptado de Campos (1996, p. 269).

Analisando-se o PDCA na figura 8, constata-se que o resultado está diretamente ligado a adoção de um plano de ação efetivo, Campos sugere a adoção do modelo $5 \mathrm{~W} 1 \mathrm{H}$, sendo esta sigla as inicias de seis palavras da língua inglesa: What - o quê -, Who - quem -, When - quando -, Where - onde -, Why - por quê - e How - como - (CAMPOS, 1998). O plano 
de ação deve responder a estes seis questionamentos e ter por objetivo atacar as causas do não-atingimento das metas identificadas na análise.

\section{CRIAÇÃO DO CONHECIMENTO}

A capacidade competitiva está ligada à capacidade de criar conhecimento na organização. Nonaka e Takeuchi (1997, p. 1), relatam que "por criação do conhecimento organizacional entendemos a capacidade de uma empresa de criar conhecimento, difundi-lo na organização como um todo e incorporá-lo a produtos, serviços e sistemas". O conhecimento na empresa é criado nas dimensões epistemológica e ontológica.

Nonaka e Takeuchi (1997, p. 103) relatam que na “(...) dimensão epistemológica (...) é onde ocorre a conversão do conhecimento de conhecimento tácito para conhecimento explicito". Conforme os autores, isto ocorre através dos quatro modos de conversão socialização, externalização, combinação e internalização - e das cinco condições organizacionais - intenção, flutuação / caos, autonomia, redundância e variedade de requisitos - a serem comentadas no próximo tópico. Nonaka e Takeuchi (1997, p. 103) relatam também que "Na dimensão ontológica (...) o conhecimento criado pelos indivíduos é transformado em conhecimento em nível de grupo e em nível organizacional".

O conhecimento humano é criado e expandido pela interação social entre o conhecimento tácito e o conhecimento explícito, ou seja, pela necessidade de transmitir um conhecimento adquirido ou compô-lo com outra pessoa. Esta interação social entre indivíduos é chamada de conversão do conhecimento. Para estes autores o conhecimento é dividido em quatro tipos de conversão, sendo estes: socialização, externalização, combinação e internalização (NONAKA e TAKEUCHI, 1997), conforme figura 10.

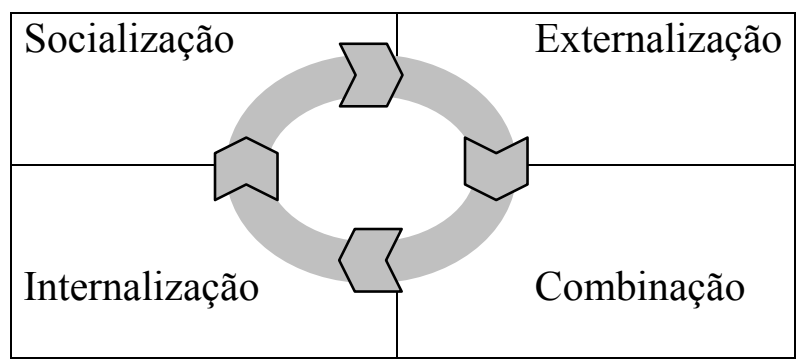

Figura 10 - Modos de conversão do conhecimento.

Fonte: Adaptado de Nonaka; Takeuchi (1997). 
$\mathrm{Na}$ socialização os indivíduos compartilham conhecimento tácito através de conversas e de experiências conjuntas. É através da socialização que uma pessoa conhece o raciocínio da outra pessoa compartilhando com este seu raciocínio. Nonaka e Takeuchi (1997, p. 262) nos relata que "O modo de socialização começa com a formação de uma equipe cujos membros compartilham suas experiências e modelos mentais". Externalização é o uso do diálogo ou reflexão coletiva para articular o conhecimento tácito em conceitos explícitos. É a transmissão de insights, vivências e percepções dos indivíduos.

Na opinião dos autores (1997, p. 73) "a externalização é a chave para a criação do conhecimento, pois cria conceitos novos e explícitos a partir do conhecimento tácito". A utilização dos modos de conversão possibilita a criação de um espiral da criação do conhecimento, onde a cada transformação do conhecimento tácito para explícito e novamente para o tácito entre um grupo de indivíduos promove a ampliação do conhecimento. A inclusão de novos indivíduos no espiral da criação do conhecimento promove a criação do espiral da criação do conhecimento organizacional, conforme figura 11.

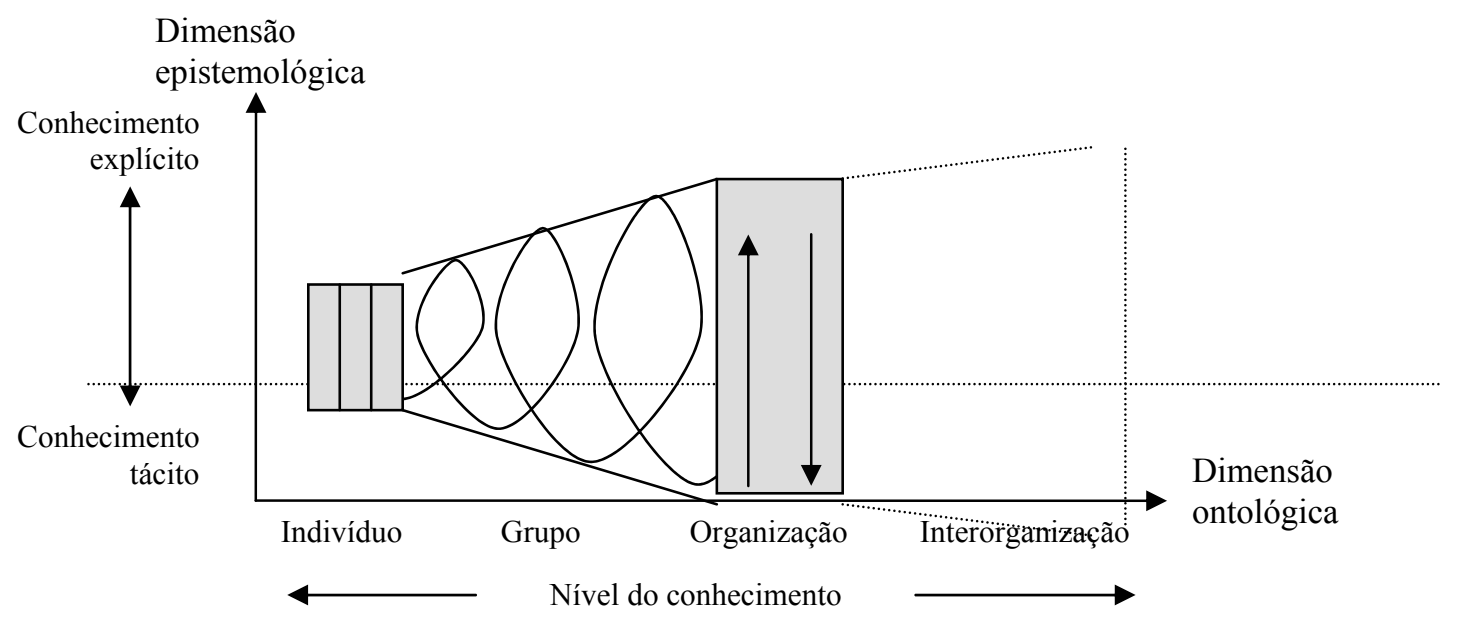

Figura 11 - Espiral da criação do conhecimento organizacional.

Fonte: Nonaka; Takeuchi (1997, p. 82).

O aprendizado contínuo promove o aprendizado individual, a troca de experiências e conhecimentos proporciona a ampliação do conhecimento coletivo na organização. Para Fleury, et al. (2001, p. 136) o "conhecimento pode ser distinto entre conhecimento do indivíduo, do grupo, da organização e da rede de organizações interagentes". Para os autores a troca de conhecimentos entre os indivíduos de um grupo proporciona a aprendizagem do modo de saber fazer. Nas palavras de Nonaka e Takeuchi (1997, p. 65) “(...) o conhecimento 
só é criado por indivíduos. (...) A organização apóia os indivíduos criativos ou lhes proporciona contextos para a criação do conhecimento". Dessa maneira, a participação da empresa é fundamental para promover a criação do conhecimento por meio da interação de seus executivos com todos os colaboradores, proporcionando um clima participativo, criando o conhecimento corporativo.

\section{OS FLUXOS DE INFORMAÇÃO NA CONCEPÇÃO DO PLANEJAMENTO ESTRATÉGICO}

Para idealização do estudo, foi realizada uma pesquisa documental sobre o tema e, pela observação participante do pesquisador na construção do planejamento estratégico de uma empresa do ramo de alimentos e bebidas, aqui denominado empresa Alfa, foi observada e relatada a geração dos fluxos de informações gerados na concepção do planejamento estratégico.

Para atender às expectativas de rentabilidade dos acionistas os executivos se mobilizam identificando oportunidades de melhoria, estas oportunidades são identificadas baseadas em informações internas e externas à empresa. Para transformar as oportunidades em resultados são definidas diretrizes estratégicas. As diretrizes estratégicas têm como propósito mobilizar a empresa, direcionando as ações para idealização dos objetivos propostos pelas diretrizes estratégicas definidas pelos executivos de nível estratégico. As ações de melhorias são realizadas no nível operacional orientadas pelo uso do PDCA. O planejamento estratégico é a soma de todas estas etapas. Todo este processo gera um fluxo de informações na pirâmide organizacional, conforme figura 12. 

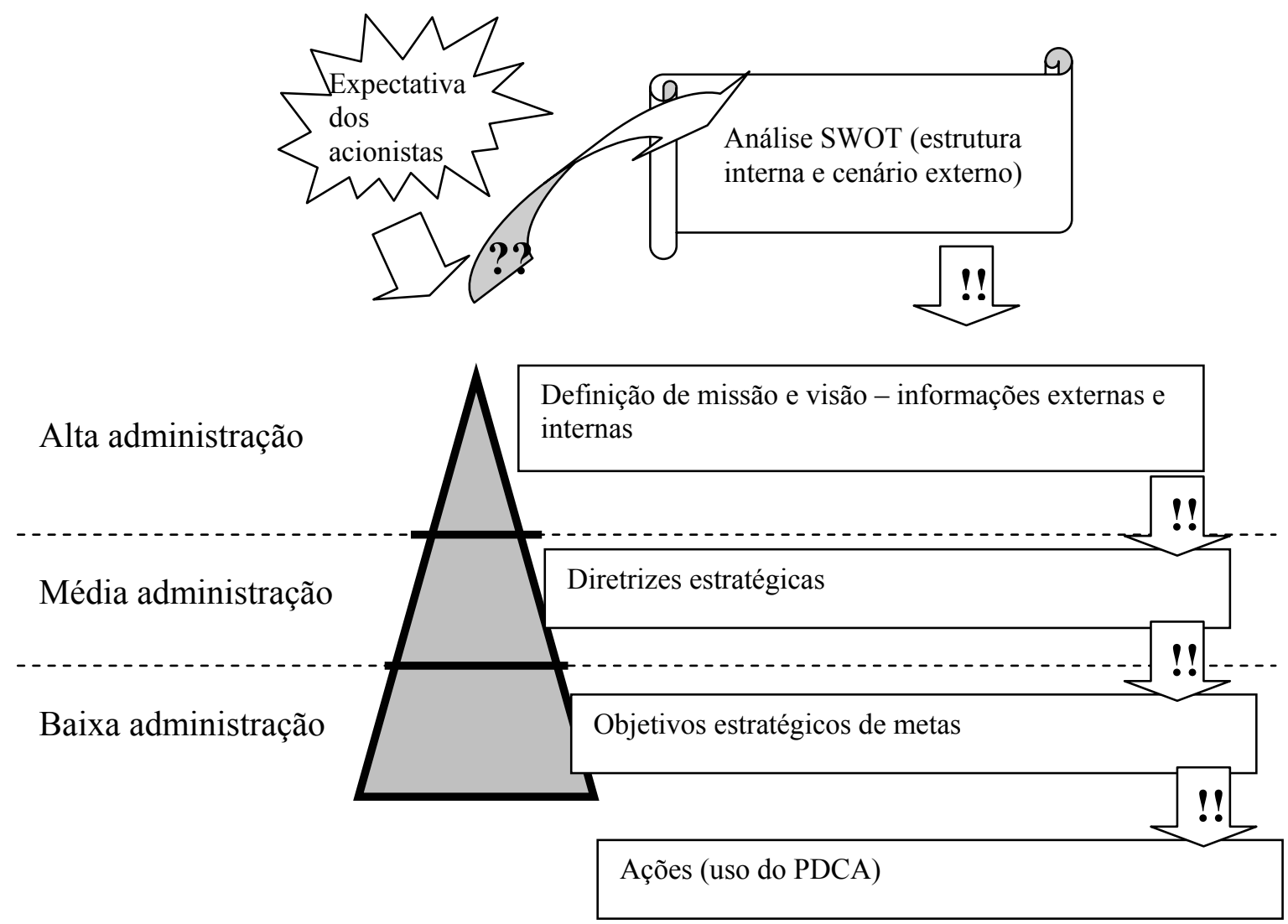

Figura 12 - Fluxo de informações na estruturação hierárquica na formulação do planejamento estratégico.

Fonte: Observação do autor na empresa Alfa.

Conforme apresentado na figura 12, a alta administração recebe dos acionistas sua expectativa de resultados. Para atender a estas expectativas, os executivos no nível estratégico desencadeiam uma série de movimentos para direcionar as ações e recursos da empresa. Todo este processo é orientado pelo planejamento estratégico. Para encontrar formas para idealizar os desejos dos acionistas, a alta administração recorre à análise de SWOT, onde são identificadas ameaças e oportunidades, bem como forças e fraquezas. Assim, na análise de SWOT são sintetizadas as informações consideradas relevantes ao plano estratégico relacionadas às finanças, mercados, processos e aprendizado.

Para que as oportunidades apresentadas pelo meio externo beneficiem a empresa são desenvolvidas diretrizes estratégicas. Estas diretrizes conduzem a objetivos e planos de ações que resultarão em melhoria do desempenho, proporcionando a realização das expectativas de rentabilidade dos acionistas. O planejamento estratégico proporciona a comunicação das diretrizes a toda a organização, alinhando toda a empresa a um objetivo único e direcionado a obtenção de resultados superiores. 
Nesta etapa, o fluxo de informações ocorre de cima para baixo na cadeia organizacional da companhia. Para atender aos desafios propostos pelo planejamento estratégico, cada área se desdobra em busca de respostas aos problemas e oportunidades identificadas em sua área. Este processo ocorre em todos os níveis da pirâmide organizacional. Cada equipe busca informações e conhecimentos na própria equipe, na organização e até fora da própria empresa. A figura 13 demonstra como ocorre este processo.

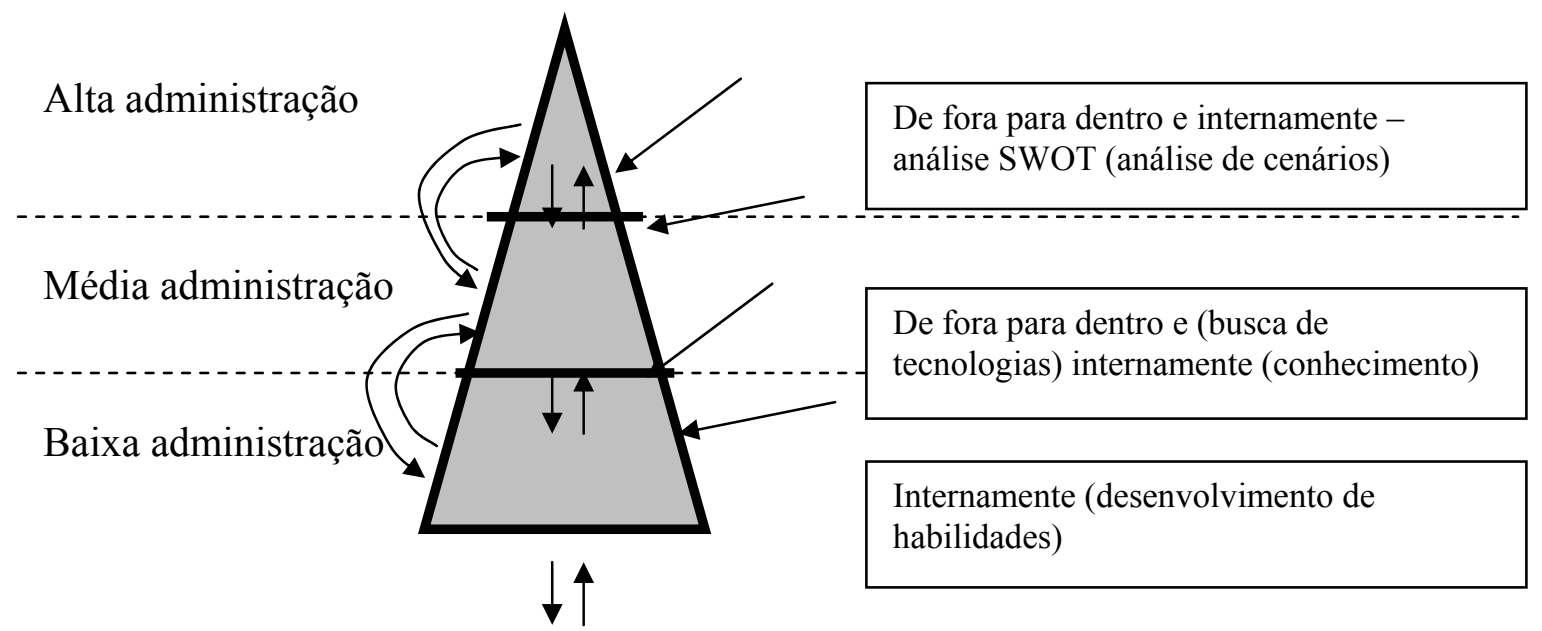

Figura 13 - Fontes de informação para concepção das ações estratégicas.

Fonte: Observação do autor na empresa Alfa.

Analisando a figura 13, percebe-se que as fontes de informações e conhecimento para concepção das ações estratégicas são de origem interna e externa. A visão crítica e construtiva das equipes proporciona a ampliação destes conhecimentos, canalizando-os a ações para melhoria dos resultados. A alta administração busca na análise externa estruturar o cenário sobre ameaças e oportunidades que a companhia está enfrentando ou que possa vir a sofrer. Esta análise visa a identificar informações referentes a produtos de concorrentes, fornecedores e até possíveis fusões e parcerias que a empresa possa implantar para tornar-se mais competitiva.

A administração do nível médio se propõe a identificar novas técnicas e tecnologias que possam melhorar de forma significativa o desempenho. Identificar novos equipamentos, novos processos, novas matérias-primas. Em todos os níveis hierárquicos, o processo de concepção e idealização do planejamento estratégico parte do conhecimento da própria equipe envolvida, o objetivo do planejamento estratégico é ampliar este conhecimento através de trocas de experiências e de adição de informações e conhecimentos externos necessários para 
atender à expectativa dos acionistas da empresa. Para que o conhecimento criado proporcione melhoria na revisão do planejamento estratégico, é solicitado aos envolvidos que concedam aos seus superiores hierárquicos um feedback do desenvolvimento do planejamento estratégico, conforme figura 14.

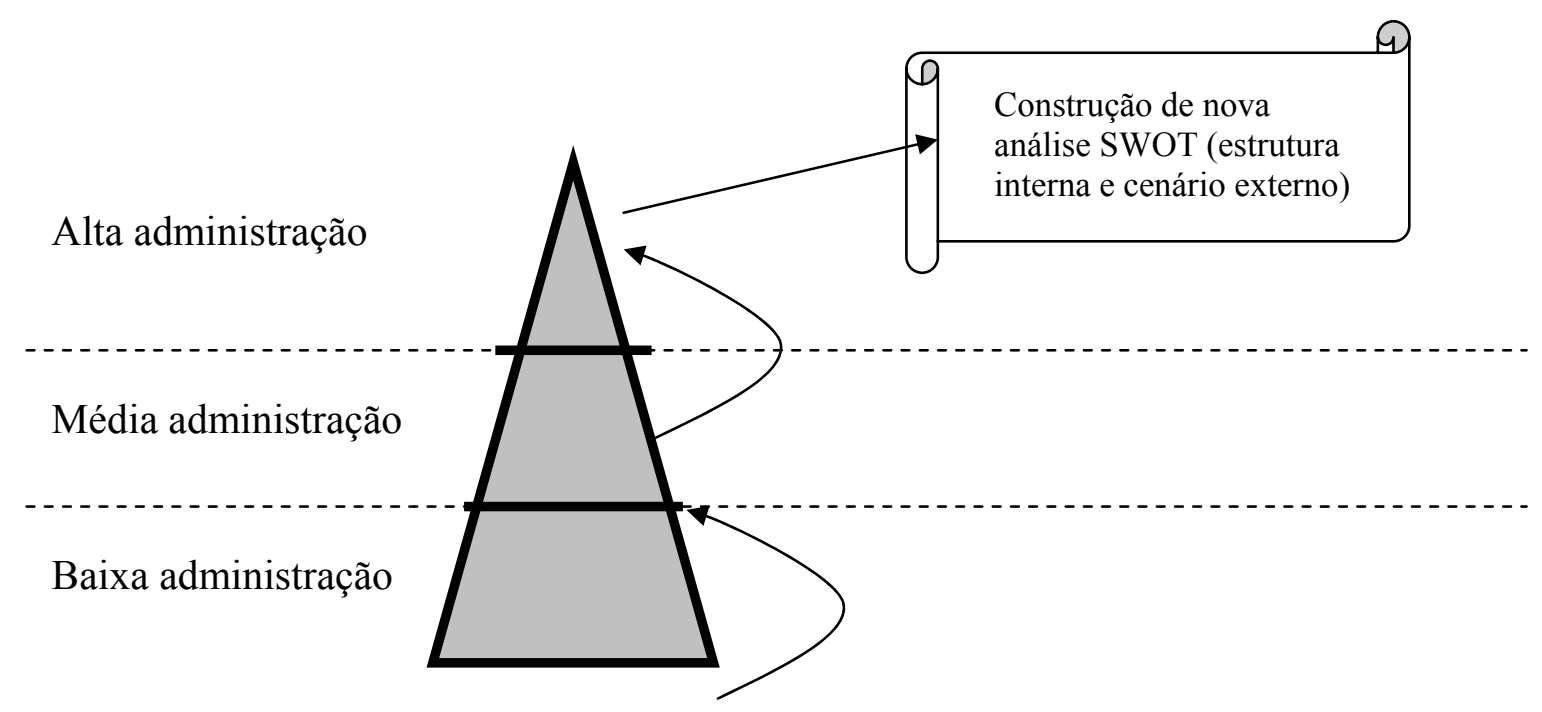

Figura 14 - Processo de feedback.

Fonte: Observação do autor na empresa Alfa.

Este processo de feedback proporciona o enriquecimento de informações para construção da nova análise de SWOT ainda mais precisa. Uma análise de SWOT mais precisa proporcionará o desenvolvimento de ações mais assertivas, proporcionando a obtenção de resultados superiores à organização. Com o feedback encerra-se o ciclo de aprendizagem, proporcionando a cada revisão o desenvolvimento de mais um ciclo de aprendizagem. Ao longo dos anos percebe-se o desenvolvimento do espiral do conhecimento. Analisando-se os fluxos de informações e desenvolvimento de novos conhecimentos desenvolvidos em cada etapa da concepção do planejamento estratégico percebe-se que este processo é uma importante forma de criação e disseminação de conhecimento na organização.

\section{CONCLUSÃO}

A competência de um gestor está diretamente ligada à sua capacidade de reverter uma situação competitiva desfavorável da empresa, tornando sólida a capacidade de realização de resultados positivos. Empresas que vêm obtendo êxito neste desafio utilizam o conhecimento como base competitiva, agregando conhecimento a seus produtos e serviços. 
Com base na revisão bibliográfica e nos resultados que a empresa Alfa vem apresentando, constatou-se a efetividade da utilização do planejamento estratégico, culminando com a realização de resultados superiores utilizando-se uma ferramenta adequada para disseminação das diretrizes estratégicas e de fornecimento de feedback.

O objetivo deste estudo foi de analisar como os fluxos de informações gerados na concepção e realização do planejamento estratégico provocam a criação do conhecimento organizacional e, por conseqüência, a gestão dos 'diferentes conhecimentos' na organização possibilita a formulação de um adequado planejamento estratégico.

O trabalho mostrou que este processo proporciona fluxo de informações partindo de várias fontes, possibilitando a disseminação e criação de conhecimento em toda a empresa, ampliando o conhecimento organizacional. A estruturação de um planejamento estratégico utilizando o modelo proposto mostrou-se adequado para alinhar as ações de toda a empresa, proporcionando à empresa o melhor aproveitamento de oportunidades reduzindo os pontos fracos e ampliando os pontos fortes, oportunizando a participação de todos os colaboradores, contribuindo com a soma dos diferentes conhecimentos. Essa participação torna evidente a ocorrência do espiral de conhecimento.

Este trabalho resultou de uma pesquisa como observador participante na empresa denominada Alfa, resultando na monografia para obtenção do título de especialista em Gestão Industrial no Curso de Pós-Graduação em Gestão Industrial, Departamento de PósGraduação, CEFET-PR, Unidade de Ponta Grossa no ano de 2004.

Este estudo será continuado, em parte no curso de Mestrado em Engenharia Industrial, na mesma instituição (hoje denominada, Universidade Tecnológica Federal do Paraná), onde serão realizados testes práticos para a confirmação deste estudo. 


\section{REFERÊNCIAS}

Análise empresa em evidência, Disponível em: < http://www.solidus.com.br/semanal.asp > Acessado em: 05/05/2004.

CAMPOS, V. F. Gerenciamento pelas diretrizes. Belo Horizonte: Fundação Christiano Ottoni, Escola de Engenharia da UFMG, 1996.

CAMPOS, V. F. Gerenciamento da rotina do trabalho do dia-a-dia. 6 ed. Belo Horizonte: Editora de desenvolvimento gerencial, 1998.

DRUCKER, P. F. Introdução à Administração. 3 ed. São Paulo: Pioneira, 1998.

FLEURY, M. T. L. et al. Gestão estratégica do conhecimento: integrando aprendizagem, conhecimento e competências. São Paulo: Atlas, 2001.

GITMAN, L. J. Princípios de administração financeira. 7. ed. San Diego State University: Harba, 2002.

HINDLE, T.; LAWRENCE, M. Field Guide to Strategy: A Glossary of Essencial Tools and Concepts of Today Managers. Harvard Business School Press, 1994.

IUDÍCIBUS, S. de; MARION, J. C. Dicionário de termos de contabilidade. São Paulo: Atlas, 2001.

KAPLAN, R. S.; NORTON D. P. A estratégia em ação: balanced scorecard. 10 ed. Rio de Janeiro: Campus, 1997.

KOTLER, P. Marketing. edição compacta. São Paulo, Atlas, 1980.

NONAKA, I.; TAKEUCHI, H. Criação de conhecimento na empresa. 13 ed. Rio de Janeiro: Campus, 1997.

OLIVEIRA, D. de P. R. de. Planejamento estratégico: conceitos, metodologia e prática. 15 ed. São Paulo: Atlas, 2001.

OLIVEIRA, L. M. de; PEREZ Jr., J. H.; SILVA, C. A. dos S. Controladoria estratégica. São Paulo: Atlas, 2002.

PORTER, M. E. Vantagem competitiva. Rio de Janeiro: Campus, 1990.

PROBST, G.; RAUB, S.; ROMHARDT, K. Gestão do conhecimento: Os elementos construtivos do sucesso. Porto Alegre: Bookman, 2002.

WAHBA, C. Geração de riqueza através de inteligência gerencial. Rio de Janeiro: Qualitymark, 2002. 